\title{
Desenvolvimento sustentável e a produção de biocombustíveis: uma alternativa à produção de fumo?
}

\author{
Marcos Vinicius Dalagostini Bidarte \\ Universidade Federal do Rio Grande (FURG) \\ Ana Monteiro Costa \\ Universidade Federal de Pernambuco (UFPE)
}

Recebido: 27/12/2016 Versão revisada (entregue): 29/06/2017 Aprovado: 29/06/2018

\begin{abstract}
Resumo
Na perspectiva do desenvolvimento sustentável como processo que visa à melhoria de vida das pessoas e da adesão do Brasil à Convenção-Quadro para o Controle do Tabaco, o presente estudo buscou verificar se a produção de biocombustíveis de primeira geração pode ser uma alternativa aos municípios produtores de fumo no Vale do Rio Pardo, Rio Grande do Sul. Para compreender o vínculo dos agricultores com o cultivo de matérias-primas para biocombustíveis de primeira geração em relação à substituição da produção de fumo e/ou à diversificação da propriedade rural, realizou-se um estudo de caso múltiplo, com entrevistas direcionadas a quatro agricultores que possuíam relação com os Projetos Girassol e Etanol protocolados pela AFUBRA. Os resultados revelam que a produção de biocombustíveis é uma alternativa sustentável no que tange à diversificação da propriedade, mas com considerável redução de ganhos e dificuldades de cultivo em terrenos acidentados. Os incentivos para a produção de biocombustíveis são os benefícios à saúde dos agricultores, a redução de gastos com combustíveis fósseis, a geração de renda aos produtores e a preservação do meio ambiente.
\end{abstract}

Palavras-chave | Biocombustíveis; desenvolvimento sustentável; fumo; Projeto Etanol; Projeto Girassol; Vale do Rio Pardo.

Código JEL |O13; Q16; Q42.

\section{SUSTAINABLE DEVELOPMENT AND THE PRODUCTION OF BIOFUELS: AN ALTERNATIVE TO TOBACCO PRODUCTION?}

\begin{abstract}
Considering the Sustainable Development as the process which aims to improve the welfare of the people and the adhesion of Brazil to the Framework-Convention for the Control of the Tobacco, the current article aims to verify if the production of biofuels of first generation could become an alternative for the Sustainable Development of the inner cities of Rio Pardo and of Sinimbu, Brazil. To understand the linkage of farmers with the production of biofuels of first
\end{abstract}


generation in relation the replacement of tobacco production and/or the diversification of the rural property in the development of this region, was conducted a multiple case study. It was done with interviews at four farmers, which had relation with the Projects Sunflower and Ethanol registered by AFUBRA. The results obtained show that the production of biofuels is a viable and sustainable alternative in terms of the diversification of the rural property. However, there are considerable reduction of monetary gains and difficulties of cultivation in rough terrains. The main stimulus for the implementation of biofuels production are the benefits related to the health of the farmers, to the reduction of spending on the purchase of fossil fuels and the generation of income to farmers and the preservation of the environment.

Keywords | Biofuels; Project Sunflower; Project Ethanol; Rio Pardo Valley; sustainable development; tobacco.

JEL-Code |O13; Q16; Q42.

\section{DESARROLLO SOSTENIBLE Y LA PRODUCCIÓN DE BIOCOMBUSTIBLES: ¿UNA ALTERNATIVA A LA PRODUCCIÓN DE TABACO?}

\section{Resumen}

Considerando el desarrollo sostenible como proceso que busca elevar el nivel de vida de las personas y la adhesión de Brasil al Convenio Marco para el Control del Tabaco, el presente estudio tuvo como propósito verificar si la producción de biocombustibles de primera generación puede ser una alternativa en los municipios productores de tabaco en el Vale do Rio Pardo, Rio Grande do Sul. Para entender el vínculo de los agricultores con el cultivo de materias primas para biocombustibles de primera generación en relación con la sustitución de la producción del tabaco y/o la diversificación de la propiedad rural, fue ejecutado un estudio de caso múltiple, con entrevistadas dirigidas a cuatro agricultores que tenían relación con los Proyectos Girasol y Etanol registrados por AFUBRA. Los resultados revelan que la producción de biocombustibles es una alternativa sostenible respecto a la diversificación de la propiedad, pero con una reducción considerable de las ganancias y dificultades de cultivos en terrenos accidentados. Los incentivos para la producción de biocombustibles son los beneficios generados para la salud de los agricultores, la reducción de gastos con combustibles fósiles, la generación de ingresos para los productores y la preservación del medio ambiente.

Palabras-clave | Biocombustibles; desarrollo sostenible; tabaco; Proyecto Etanol; Proyecto Girasol; Vale do Rio Pardo.

Código JEL | O13; Q16; Q42.

\section{Introdução}

O progresso dos debates mundiais, no decorrer do século XX, sobre as propostas que visam preservar o meio ambiente, desencadeou a descoberta de novas fontes 
de energia, a partir da utilização dos elementos naturais ${ }^{1}$ e de energias alternativas ou renováveis. Neste contexto, os biocombustíveis apresentam-se como uma energia renovável (FERES, 2010). A utilização de biocombustíveis diminui as emissões de dióxido de carbono na atmosfera, reduz as emissões de gases de efeito estufa e atua no processo de substituição do petróleo e seus derivados (WEID, 2009).

Com essa alternativa de energia, o Brasil incorpora na sua matriz energética os dois biocombustíveis de primeira geração ${ }^{2}$, o etanol e o biodiesel, como reação às duas crises do petróleo (ABRAMOVAY, 2008; FERES, 2010). O etanol passou a ser produzido a partir da cana-de-açúcar e o biodiesel a partir da soja, da mamona, e, principalmente, do dendê (BARBOSA, 2007; FERES, 2010). Tal incorporação teve por finalidade atuar na diminuição da dependência externa brasileira de petróleo, que estava impactando fortemente na balança de pagamentos (LEITE; LEAL, 2007).

De modo geral, em um primeiro momento a substituição do petróleo e seus derivados por biocombustíveis de primeira geração teve um viés puramente econômico, na medida em que o país economizava divisas diminuindo a importação deste (ABRAMOVAY, 2008; LEITE; LEAL, 2007). Contudo, no decorrer do processo de substituição do petróleo, percebeu-se que o país apresentava condições propícias para a produção de biocombustíveis, e que essa atuaria reduzindo os impactos ambientais (FERES, 2010).

Diante das condições favoráveis à sua produção e a maior preocupação com o meio ambiente, o cultivo de matéria-prima para biocombustíveis também passou a ser visto como um meio para promover a sustentabilidade ambiental para além do setor de combustíveis, podendo substituir outras culturas danosas ao meio ambiente e às pessoas (FERES, 2010), como o fumo (ETGES et al., 2002). O Brasil, um dos principais produtores mundiais de fumo, aderiu à ConvençãoQuadro sobre Controle do Uso do Tabaco, em 2003, quando passou a adotar a posição de "protetor" das gerações presentes e futuras dos riscos sociais, econômicos e ambientais oriundos do consumo e da exposição à fumaça do tabaco. Posteriormente, em 2005, o país lançou o Programa Nacional de Diversificação em Áreas Cultivadas com Tabaco, com o objetivo principal da diversificação produtiva em propriedades rurais familiares (MDA, 2014).

\footnotetext{
${ }^{1}$ Optou-se por utilizar no texto o termo "elemento", uma vez que "recurso" está vinculado a uma análise economicista da natureza. No entanto, nas referências e citações, mantemos o sentido dado pelos autores.

2 A categoria "primeira geração" refere-se aos biocombustíveis produzidos através de fontes agrícolas primárias, como por exemplo, o etanol de cana-de-açúcar ou milho e o biodiesel de girassol (FERES, 2010; WEID, 2009).
} 
Do semeio à colheita, o cultivo do fumo destaca-se pelo uso exacerbado de agrotóxicos, o que acarreta sérios riscos à saúde dos agricultores, como doenças diversas e mortes (DESER, 2009; ETGES et al., 2002; OLIVEIRA et al., 2010; RIQUINHO; HENNINGTON, 2014), e danos ao meio ambiente (ETGES et al., 2002; OLIVEIRA et al., 2010). Contudo, esta produção persiste nos municípios de Sinimbu e de Rio Pardo, ambos localizados na região do Vale do Rio Pardo, no Rio Grande do Sul, Brasil, principalmente pelo alto retorno financeiro apresentado aos agricultores, proprietários de pequenas áreas, em comparação com outras culturas tradicionais (KONZEN; ROHR, 1988; VARGAS, 2013; WEGNER; SANTOS; PADULA, 2010).

Deste modo, o desenvolvimento da região está atrelado à produção de fumo. $\mathrm{O}$ fator econômico atua como um entrave à adesão, pelos agricultores, a programas nacionais e projetos que visam à diversificação da propriedade, à substituição do fumo por culturas mais sustentáveis e à geração de novas fontes de renda à agricultura familiar (FERES, 2010; WEGNER; SANTOS; PADULA, 2010). O Vale do Rio Pardo é um exemplo da alta dependência da cadeia produtiva do fumo, e que busca propor, aos agricultores, alternativas diversificadoras da propriedade e complementadoras de renda. Quanto a isso, em diversas partes do Brasil há projetos públicos e privados estimulando a produção de biocombustíveis e tangenciando o desenvolvimento regional sustentável.

Diante deste contexto, o presente estudo possui o objetivo de verificar se a produção de biocombustíveis de primeira geração pode ser uma alternativa de Desenvolvimento Regional Sustentável aos municípios gaúchos produtores de fumo de Rio Pardo e de Sinimbu, Brasil. Assim sendo, apresenta-se, na seção a seguir, o referencial teórico, com: I) o surgimento e a evolução do conceito do Desenvolvimento Sustentável, II) os biocombustíveis, expondo os seus benefícios e malefícios em relação à sua produção, tendo como referência os Pilares da Sustentabilidade, e III) a descrição do desenvolvimento regional do Vale do Rio Pardo e da produção fumageira nos municípios gaúchos de Sinimbu e de Rio Pardo. Após, são apresentados os procedimentos metodológicos. A análise dos dados e as considerações finais compõem a penúltima e a última seções, respectivamente.

\section{Desenvolvimento Sustentável}

O Desenvolvimento Sustentável pode ser considerado como o maior movimento mundial da atualidade (BARBIERI; CAJAZEIRA, 2009), pois a sua origem está pautada fortemente nas grandes discussões e movimentações populares sobre o aprofundamento intensivo da degradação ambiental e os riscos que dela decorrem (BRÜZEKE, 1993). Concomitantemente com as questões ambientais que estavam emergindo na década de 1960, ingressou em pauta a dessemelhança entre o 
desenvolvimento e o crescimento econômico. $\mathrm{O}$ desenvolvimento deveria estar atrelado mais à melhoria de qualidade de vida da população, e não unicamente ao enriquecimento do país (FURTADO, 2000). Quanto a isso, em 1968 é fundado o Clube de Roma, com a participação da sociedade civil, cientistas, físicos, políticos e industriais do então denominado Primeiro Mundo, que trataram do Desenvolvimento Sustentável da Terra (CLUB OF ROME, 2014).

No ano de 1972, surge a Conferência Mundial sobre Meio Ambiente Humano, ou Conferência de Estocolmo, inaugurando uma série de debates no âmbito ambiental, dentro de um cenário de ciclos sociais da Organização das Nações Unidas (ONU). A criação do conceito de Desenvolvimento Sustentável, em 1972, foi embasada em um processo que visou atender as necessidades da atual geração sem que houvesse o comprometimento do bem-estar das gerações futuras. Evidencia-se que a Conferência de Estocolmo não preestabeleceu o modo como cada nação deveria utilizar e gerir seus recursos naturais, porém, com o passar das décadas, muitos dos princípios estabelecidos pela Conferência foram transformados em metas e elementos de negociação (LAGO, 2006; SCOTTO; CARVALHO; GUIMARÃES, 2008).

Em 1983, a Comissão Mundial sobre Meio Ambiente e Desenvolvimento iniciou os seus trabalhos a partir dos problemas socioeconômicos e ecológicos enfrentados na época, e que vinham tomando repercussão global. A Comissão acentuou a interligação que havia entre os problemas e a política, a economia, a sociedade e a tecnologia, e trouxe, ainda, a noção de sustentabilidade (BRÜZEKE, 1993). Em 1987, a Comissão aconselhou a elaboração de uma declaração universal a respeito da proteção ambiental e do Desenvolvimento Sustentável: o relatório Brundtland. O relatório elencou uma série de medidas a serem incorporadas pelas instituições internacionais e também pelos Estados-Nação, com vistas a atingir o Desenvolvimento Sustentável. O relatório obteve grande aceitação, principalmente pelo tom diplomático, pela referência sutil sobre os interesses nacionais, com extrema cautela, e a não destituição do crescimento econômico (LAGO, 2006).

O relatório Brundtland foi publicado com o título "Nosso Futuro Comum" e trouxe para debate os problemas ambientais e as preocupações em relação à velocidade das mudanças climáticas, além de apontar para a incompatibilidade entre os padrões de produção e consumo e o Desenvolvimento Sustentável. O conceito de Desenvolvimento Sustentável está direcionado para um processo que seja favorável ao meio ambiente e à sociedade, tendo os seus pilares voltados para a harmonia entre o social, o ambiental e o econômico (BARBIERI; CAJAZEIRA, 2009). Este documento foi o responsável pela versão mais difundida mundialmente do conceito de Desenvolvimento Sustentável.

Assim, o Desenvolvimento Sustentável se dá com a harmonização entre as dimensões Social, Ambiental e Econômica, aqui tratadas por Pilares, sem que uma se sobreponha a outra em importância. Em relação aos Pilares da Sustentabilidade, 
o Pilar Social trata das potencialidades e habilidades humanas, do bem-estar dos indivíduos no âmbito de seus trabalhos, de suas saúdes e de suas famílias, da integração dos indivíduos na sociedade e da educação. O Pilar Econômico aborda a produção e o acesso ao mercado, realiza a análise da distribuição e do consumo das pessoas quanto a bens e serviços e escoamento da produção, com o intuito de verificar se a atividade produtiva é economicamente sustentável. Já o Pilar Ambiental versa sobre os elementos naturais, latentes na natureza, sendo que neste pilar se deve pensar no curto, no médio e no longo prazo de forma que todas as atividades desenvolvidas pela sociedade utilizem o mínimo possível de recursos naturais (BARBIERI; CAJAZEIRA, 2009; SCOTTO; CARVALHO; GUIMARÃES, 2008).

Somente na década de 1990 a sociedade civil demonstrou preocupação com a sua qualidade de vida e com a natureza, passando a importar-se menos com o crescimento econômico. Neste momento, surge a Declaração sobre Meio Ambiente e Desenvolvimento, ou Rio-92, realizada no Rio de Janeiro, Brasil, em 1992. A Rio-92 teve como principal preocupação trazer o debate sobre a relevância de respostas globais para as questões ambientais e a evolução da degradação ambiental em nível internacional. O documento ficou mundialmente conhecido por ser a declaração com maior importância acerca de assuntos sobre a integração entre o meio ambiente e o desenvolvimento e também por seus fracassos em relação às medidas de proteção ambiental (AGUIAR, 2010; SCOTTO; CARVALHO; GUIMARÃES, 2008).

Duas décadas após, surge a Conferência das Nações Unidas sobre Desenvolvimento Sustentável, ou Rio+20. Esta Conferência foi considerada a maior dentre as já convocadas pela ONU, e teve como objetivo principal a implantação do Desenvolvimento Sustentável. Ao término da Rio+20, 188 países comprometeram-se a realizar ações visando proporcionar resultados positivos econômicos, sociais e ambientais no âmbito internacional (ONU, 2012), porém o desafio da redução das emissões de dióxido de carbono está constantemente impossibilitando o avanço do acordo, em função da irredutibilidade de alguns países em aderirem às metas propostas. Um dos meios de amenização da poluição passa a ser a substituição de combustíveis fósseis pelos biocombustíveis, conforme se apresenta na seção seguinte.

Percebe-se que foram necessários longos anos e inúmeras discussões para aproximar-se de um consenso mundial sobre o convívio e a utilização do meio ambiente em relação aos pressupostos do Desenvolvimento Sustentável. Muitos encontros não foram bem sucedidos, frustrando expectativas. Uma parcela importante desse fracasso deve-se à desigualdade de poder entre os países e ao uso de forças econômicas e políticas como forma de defender os seus interesses nacionais, sendo o meio ambiente um pilar eminentemente global. Assim, o Desenvolvimento Sustentável é um conceito em construção, com uma teoria em igual situação, perpassando por um debate ético. 


\section{Alternativas Sustentáveis de Energia: Os Biocombustíveis}

Os biocombustíveis, ou agrocombustíveis, são combustíveis de origem vegetal e animal, que podem ser utilizados visando à redução do uso de combustíveis fósseis e, consequentemente, as emissões de gases de efeito estufa, em particular o dióxido de carbono, caracterizando, assim, uma alternativa para enfrentar a questão do aquecimento global. No Brasil, a produção de biocombustíveis de primeira geração deu-se em resposta às duas crises do petróleo, de 1973 e de 1979 (FERES, 2010; LEITE; LEAL, 2007; WEID, 2009).

O pioneirismo do Brasil em estabelecer um programa de incentivo à produção e ao uso do álcool foi determinado em 1975, com a criação do Programa Nacional do Álcool, através do Decreto n. 76.593, definindo, assim, o papel do etanol a longo prazo. O programa foi elaborado a partir de metas econômicas e visando à substituição do petróleo pelo etanol, para que o Brasil alcançasse uma eficiência energética aliada a custos competitivos. Por outro lado, a produção de biodiesel iniciou-se com a cultura do dendê, entre as décadas de 1960-1970, devido às oscilações dos preços internacionais do petróleo, sendo estabelecido pelo governo federal, em 2003, o Programa Nacional de Produção e Uso de Biodiesel (ABRAMOVAY, 2008; FERES, 2010; LEITE; LEAL, 2007).

Os dois biocombustíveis de primeira geração mais utilizados atualmente são o etanol e o biodiesel. O etanol (álcool etílico) é produzido principalmente a partir de cana-de-açúcar ou de milho, mas também do trigo, da beterraba e da mandioca. Já o biodiesel, pode ser obtido através de gordura animal, de óleo de fritura e de uma variedade considerável de espécies vegetais, como o dendê (palma), a soja, a mamona, a colza, o girassol, o pinhão manso, o algodão, o babaçu, o amendoim, o nabo forrageiro, a macaúba, a papoila, o abacate, o coco, o tungue (BARBOSA, 2007; FERES, 2010; LEITE; LEAL, 2007; WEGNER; SANTOS; PADULA, 2010; WEID, 2009), entre outros.

Apesar de apresentarem vantagens perante os combustíveis fósseis, sua produção e utilização também acarretam ônus. O Quadro 1 apresenta, de forma sucinta, alguns benefícios e malefícios promovidos pelos biocombustíveis. 


\section{Quadro 1 - Benefícios e malefícios promovidos pela produção e utilização de biocombustíveis}

\begin{tabular}{|c|c|c|}
\hline $\begin{array}{c}\text { Pilares da } \\
\text { Sustentabilidade }\end{array}$ & Benefícios & Malefícios \\
\hline Pilar Social & $\begin{array}{l}\text { Promovem a inclusão social e da } \\
\text { agricultura familiar e atuam na } \\
\text { redução da mão de obra infantil } \\
\text { e de trabalhadores sem carteira } \\
\text { assinada. }\end{array}$ & $\begin{array}{l}\text { Possuem a tendência de } \\
\text { expulsarem os produtores pela } \\
\text { agricultura de grande escala e de } \\
\text { tornarem vulnerável a agricultura } \\
\text { familiar, com condições } \\
\text { precárias de trabalho e utilização } \\
\text { da mão de obra infantil e } \\
\text { análogas à escrava. }\end{array}$ \\
\hline $\begin{array}{c}\text { Pilar } \\
\text { Econômico }\end{array}$ & $\begin{array}{l}\text { São considerados indutores de } \\
\text { melhores indicadores } \\
\text { macroeconômicos de regiões e } \\
\text { países importadores de } \\
\text { combustíveis fósseis e geradores } \\
\text { de renda aos agricultores. }\end{array}$ & $\begin{array}{l}\text { Apresentam pouca } \\
\text { produtividade gerada por } \\
\text { determinadas culturas por } \\
\text { hectare plantado. }\end{array}$ \\
\hline Pilar Ambiental & $\begin{array}{l}\text { Possuem a característica de } \\
\text { serem renováveis e } \\
\text { estabilizadores dos gases de } \\
\text { efeito estufa e de ajudarem a } \\
\text { diminuir a dependência de } \\
\text { combustíveis fósseis. }\end{array}$ & $\begin{array}{l}\text { Geram prejuízos à fauna e à } \\
\text { flora devido à promoção da } \\
\text { intensificação da utilização da } \\
\text { monocultura e de agrotóxicos e a } \\
\text { dependência de vastas áreas } \\
\text { cultiváveis para a produção } \\
\text { determinadas culturas. }\end{array}$ \\
\hline
\end{tabular}

Fonte: Elaborado pelos autores de acordo com Abramovay (2008), Balsadi (2007), Barbosa (2007), Costa e Prates (2004), Feres (2010), Leite e Leal (2007), Wegner, Santos e Padula (2010) e Weid (2009).

Ainda que consideradas as restrições para as alternativas postas, vários países estão promovendo programas nacionais baseados nos princípios do Desenvolvimento Sustentável, objetivando práticas produtivas sustentáveis e geradoras de renda. O Brasil, por exemplo, desde 2005, realiza ações através do Programa Nacional de Diversificação em Áreas Cultivadas com Tabaco, com o intuito de diversificar a produção de fumo com culturas vinculadas à produção de alimentos ou de energias. Nesse sentido, o Programa não somente busca promover uma cultura mais vinculada a sustentabilidade, como substituir uma já reconhecida como danosa, tanto à saúde do consumidor e do produtor, como ao meio ambiente.

Estas ações governamentais se devem ao alto grau de comprometimento apresentado pelas propriedades rurais fumicultoras com a sustentabilidade social, econômica e ambiental. No entanto, além das limitações das políticas, em 
comparação com algumas culturas, como a do fumo, essa produção se mostra desvantajosa, como se verifica na próxima seção, que aborda a produção de fumo nos municípios gaúchos de Sinimbu e de Rio Pardo, ambos localizados no Vale do Rio Pardo, Rio Grande do Sul, Brasil.

\section{A Produção Fumageira nos Municípios Gaúchos de Sinimbu e de Rio Pardo}

Os municípios de Sinimbu e de Rio Pardo possuem uma grande quantidade de agricultores que provêm sua renda do cultivo do fumo ${ }^{3}$. O fumo tornou-se a principal cultura agrícola para a manutenção dos agricultores e de suas famílias, principalmente no que concerne a viabilidade econômica da propriedade. O Vale do Rio Pardo representou $25 \%$ de toda a produção de fumo do Brasil, tornando a região a principal produtora do país e um dos principais polos agroindustriais do estado do Rio Grande do Sul (BONATO, 2013; ETGES et al., 2002; WEGNER; SANTOS; PADULA, 2010). Esse dado demonstra a importância que essa cultura tem para o desenvolvimento regional e o impacto que a sua substituição pode causar para o mesmo.

Especificamente, o município de Sinimbu possui 2.478 famílias produtoras de fumo, que produziram 8.228 toneladas em mais de 4.201 hectares plantados. O valor bruto da safra 2009/2010 foi de R\$55.126.260,00. Já o município de Rio Pardo possui 1.571 famílias produtoras de fumo, que produziram 7.834 toneladas em 4.043 hectares plantados. O valor bruto da safra 2009/2010 ultrapassou R\$

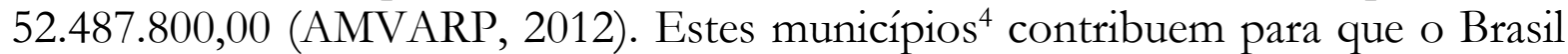
continue sendo mundialmente o maior exportador de fumo desde 1993 e o segundo maior produtor do bem (SINDITABACO, 2015; VARGAS, 2013). O Rio Grande do Sul contribuiu com $10,2 \%$ do total de fumo exportado e a região

\footnotetext{
${ }^{3} \mathrm{O}$ município de Sinimbu possui uma população estimada em 10 mil habitantes, com mais de 2 mil propriedades rurais, com tamanho médio de 25 hectares, destinadas à produção agrícola, de bens industriais e pecuários. E o município de Rio Pardo conta com uma população aproximada de 39 mil habitantes e apresenta uma produção agrícola diversificada e pecuária, com a substituição total dos campos nativos pelas pastagens melhoradas. Os municípios de Sinimbu e de Rio Pardo fazem parte do Vale do Rio Pardo e possuem a cidade de Santa Cruz do Sul como o principal polo da região (RIO PARDO-RS, 2014; SINIMBU-RS, 2014).

${ }^{4}$ Os municípios de Sinimbu e de Rio Pardo não são os maiores produtores de fumo da região do Vale do Rio Pardo. Segundo dados da AMVARP (2012), os municípios que mais produziram fumo na safra 2009/2010 foram Venâncio Aires, com uma produção total de 21.389 toneladas; Santa Cruz do Sul, com uma produção total de 15.847 toneladas; e Candelária, com uma produção total de 14.967 toneladas.
} 
Sul foi a responsável pela produção de 473 mil toneladas, alcançando o valor de US\$2.459 milhões de dólares (SINDITABACO, 2015).

Segundo o Departamento de Estudos Socioeconômicos Rurais (2009), a produção de fumo está fortemente associada às doenças e às mortes no meio rural, principalmente durante a época de colheita e em períodos chuvosos e quentes do ano, e ao uso demasiado de agrotóxicos, afetando o meio ambiente e a saúde dos indivíduos envolvidos diretamente e da população em geral das regiões produtoras. As principais doenças causadas pela nicotina no organismo humano são: alergias, náuseas, tonturas, tremedeiras, dores de cabeça, perda parcial ou total da visão, vômitos, oscilações de pressão arterial, diversos tipos de câncer, cólica abdominal, cansaço ou fraqueza muscular, intoxicações, alta propensão ao suicídio e à depressão (DESER, 2009; ETGES et al., 2002; OLIVEIRA et al., 2010).

De acordo com a Organização Mundial da Saúde (OMS) (2010), o fumante fica exposto, entre o consumo e à fumaça, em torno de 4.720 substâncias tóxicas e podendo desenvolver graves doenças fatais e incapacitantes. No Brasil, o órgão estima que o tabagismo cause 200 mil mortes por ano; no mundo esta estimativa chega a 5 milhões. Com estas consequências, a OMS interviu propondo o primeiro tratado de âmbito internacional abrangendo a saúde pública: a Convenção-Quadro sobre Controle do Uso do Tabaco, um tratado que encara o controle da oferta de fumo como uma questão ética e de responsabilidade social.

As medidas propostas pela Convenção-Quadro sobre Controle do Uso do Tabaco passam por aumento de preços e impostos, controle do comércio ilegal, apoio a atividades alternativas economicamente viáveis no lugar da cultura do fumo, etc. O Brasil entrou como membro participante e foi o segundo país a assinar, porém, a ratificação da Convenção ocorreu somente em 2005, vigorando no país em 2006, com o intuito de ser inteiramente executada e cumprida (WHOFCTC, 2014) ${ }^{5}$.

Em 2005, o país institui o Programa Nacional de Diversificação em Áreas Cultivadas com Tabaco, através do Ministério do Desenvolvimento Agrário (MDA). O programa nacional brasileiro foi baseado nos princípios do Desenvolvimento Sustentável, da segurança alimentar, da produção diversificada e de uma sociedade participativa, atuando na qualificação do processo de produção e de desenvolvimento nas áreas de fumicultura e na perspectiva da produção ecológica, mediante a redução do uso de agrotóxicos (MDA, 2014). Este programa é extremamente relevante, pois incentiva os agricultores, através de auxílios financeiros, a diversificarem a sua atual produção, de forma voluntária, por outra mais sustentável vinculada à produção de alimentos ou de energias.

\footnotetext{
${ }^{5} \mathrm{O}$ decreto que promulga a Convenção-Quadro sobre Controle do Uso do Tabaco no Brasil é o Decreto $\mathrm{n}^{\circ}$ 5.658, de 2 de janeiro de 2006. Atualmente, todas as medidas da Convenção estão sendo estabelecidas pela Política Nacional de Controle do Tabaco.
} 
Após a implementação do programa, a Associação dos Fumicultores do Brasil (AFUBRA) protocolou dois projetos de pesquisa de caráter experimental: o primeiro, em 2006, a partir do girassol, visando à produção de biodiesel e de ração animal, em parceria com a Universidade de Santa Cruz do Sul (UNISC) e com o apoio financeiro do MDA; o segundo, a partir de cana-de-açúcar, em 2008. O Projeto Etanol foi desenvolvido em uma área experimental de cana-de-açúcar, na unidade de bioenergia da AFUBRA, localizada no município de Rio Pardo, avaliando o processo industrial, o custo de produção e a utilização do biocombustível gerado nos veículos da Associação. E o Projeto Girassol foi desenvolvido em parceria com os agricultores da região do Vale do Rio Pardo e do Vale do Taquari. Neste Projeto, a AFUBRA requisitava 1 hectare de terra (lavouras experimentais) e mão de obra dos agricultores, e em contrapartida, a Associação fornecia sementes, implementos, insumos agrícolas e assistência técnica gratuita para a realização do Projeto (AFUBRA, 2014).

Em ambos os projetos, foi verificada a viabilidade técnica das culturas e estudadas as variáveis determinantes de suas viabilidades econômicas, para que fossem propostos aos agricultores produtores de fumo como novas alternativas complementadoras de renda e diversificadoras da propriedade, contribuindo, assim, para o desenvolvimento regional. O Projeto Etanol concluiu que existia a possibilidade técnica do plantio de cana-de-açúcar nas propriedades, porém mostrou-se inviável pelo alto custo de mão de obra durante as etapas do corte e moagem; e o Projeto Girassol concluiu que as diferentes condições climáticas e os diversos tipos de solo e topografias atuam sobre a produtividade do girassol, demonstrando que a cultura pode ser considerada um atrativo para o produtor, porém, do ponto de vista econômico, somente mostrou-se viável com uma produtividade média de $2.000 \mathrm{~kg} / \mathrm{ha}$. De acordo com o boletim técnico publicado pela AFUBRA, tanto o Projeto Etanol quanto o Projeto Girassol foram encerrados em 2011, pois tratavam-se de projetos experimentais (AFUBRA, 2011; 2014).

\section{Procedimentos metodológicos}

Visando compreender o vínculo dos agricultores com o cultivo de matérias-primas para biocombustíveis de primeira geração em relação à substituição da produção de fumo e/ou à diversificação da propriedade rural, adotou-se a pesquisa de caráter descritivo-exploratório, de abordagem qualitativa (COLLIS; HUSSEY, 2005). O método de pesquisa escolhido foi o estudo de caso múltiplo (YIN, 2010), relatando a realidade dos agricultores de Rio Pardo e de Sinimbu em relação à produção e à comercialização de fumo e de matérias-primas para biocombustíveis de primeira geração, à diversificação da propriedade rural e à participação nos Projetos Girassol e Etanol protocolados pela AFUBRA. 
A técnica de coletas de dados utilizada foi a entrevista semiestruturada (COLLIS; HUSSEY, 2005; GIL, 2002), direcionada a quatro homens chefes de família: 2 do município de Sinimbu e 2 do município de Rio Pardo. As entrevistas foram realizadas entre os dias 29 e 30 de maio, 7 de julho e 14 de dezembro de 2014 e tiveram a duração média de $1 \mathrm{~h}$ e $10 \mathrm{~min}$ cada. É importante ressaltar que o presente estudo não representa o total de agricultores dos municípios estudados e que a escolha dos municípios se deu pela disponibilidade de produtores a serem entrevistados indicados pela AFUBRA.

Com relação aos dados secundários, foram pesquisados no sítio da Fundação de Economia Estatística (FEE) (2014) os preços pagos ao produtor rural pela venda de uma arroba $(15 \mathrm{~kg})$ de fumo e de uma saca $(60 \mathrm{~kg})$ de milho, no período de janeiro de 2006 a dezembro de 2013. Os preços foram corrigidos pelos autores através do Índice Geral de Preços de Distribuição Interna (IGP-DI), tendo por referência o mês de dezembro de 2013.

E a técnica de análise dos dados coletados deu-se através da análise comparativa, com a finalidade de explicar os contrastes e as similitudes do grupo de sujeitos entrevistados, e da análise da percepção (COLLIS; HUSSEY, 2005). Ainda, os autores optaram por analisar os dados sobre a produção e a comercialização de fumo e de matérias-primas para biocombustíveis de primeira geração em conjunto com os Pilares da Sustentabilidade. A seguir são apresentados os dados e sua análise.

\section{A análise sobre a sustentabilidade da produção de biocombustíveis segundo agricultores de Sinimbu e de Rio Pardo}

Apesar de estar em construção, parece consenso que o Desenvolvimento Sustentável aborda os Pilares Social, Econômico e Ambiental, os quais devem se relacionar de forma holística e harmoniosa, sem se sobreporem, para satisfazer o conceito. Com relação ao impacto social causado pela produção de fumo sobre a dimensão da saúde dos agricultores entrevistados de Sinimbu, estes destacam que não diversificaram as suas atividades agrícolas por entenderem que não sofrem nenhum tipo de dano à qualidade de suas saúdes e de suas famílias, visto que sempre estiveram protegidos com equipamentos de proteção individual (máscaras, luvas, botas e capas impermeáveis) para trabalharem nas lavouras. O tempo médio de permanência destas famílias agricultoras na cultura do fumo é de 40 anos e a média de integrantes familiares foi de 5 pessoas.

Por outro lado, os entrevistados de Rio Pardo diversificaram as suas atividades agrícolas, com investimentos gradativos na pecuária leiteira. O tempo médio de permanência destas famílias agricultoras na cultura do fumo foi de 25 anos e a média de integrantes familiares foi de 6 pessoas. No momento da pesquisa, estas 
famílias desistiram do cultivo do fumo e tampouco pretendem retomá-lo. O fator que mais influenciou no processo de desistência foi o uso intensivo de agrotóxicos aplicados, do semeio à colheita, usando pulverizadores ou manualmente, além da intoxicação causada pela absorção dérmica da nicotina, ainda que utilizem equipamentos de proteção individual. Nas palavras dos agricultores de Rio Pardo: "Eu decidi pela saúde parar de plantar fumo e seguir com o leite" (Agricultor 3); "Por mim e pela minha família eu desisti de plantar fumo" (Agricultor 4).

A aplicação de agrotóxicos leva os agricultores à exposição de doses concentradas que podem ser absorvidas, na ausência de equipamentos de proteção individual, por inalação, dérmica e via oral. E a intoxicação ocorre devido a nicotina ser uma substância alcaloide e solúvel em água, e o manuseio das folhas de fumo molhadas (suor, chuva, orvalho) contribui para uma maior absorção pela pele. Os principais sintomas apresentados pelos agricultores de Rio Pardo foram dores de cabeça persistentes, náuseas, vômitos e tonturas. Ascari, Scheid e Kessler (2012), Etges et al. (2002), Oliveira et al. (2010) e Riquinho e Hennington (2014) corroboram com os resultados do presente estudo, apontando que a produção de fumo está fortemente associada a malefícios ao meio ambiente (Pilar Ambiental) e, principalmente, à saúde dos agricultores (Pilar Social).

Segundo os relatos dos agricultores entrevistados de Sinimbu e de Rio Pardo, a colheita do fumo na lavoura era realizada por membros da família cedo da manhã, quando as folhas da planta estavam com o orvalho e de forma faseada, isto é, colhiam-se primeiro as folhas próximas do chão para depois as do topo. Após a colheita, o fumo era transportado até um galpão, onde havia uma estufa, ou cura, que era destinada a secagem da folha. O processo de colheita é árduo e impõe trabalho manual, devido ao alto custo da mecanização na lavoura, fazendo com que os trabalhadores estejam sujeitos a condições de trabalho que trazem complicações ergonômicas para as suas saúdes, bem como fatores de risco ocupacionais como mecânicos (utilização de ferramentas cortantes, manuais), biológicos (bactérias, fungos, vírus), químicos (exposição a agentes químicos diversos) e físicos (calor, frio, vento, chuva).

A cultura do fumo na região Sul do Brasil caracteriza-se como uma atividade agrícola intensiva em mão de obra basicamente familiar e exploradora do trabalho infantil ${ }^{6}$, o que acarreta um efeito social negativo. $O$ agricultor entrevistado de Rio Pardo, que possui criança na família, relatou que proibiu o seu filho de ajudar nas atividades que envolvem o cultivo de fumo, primeiro por questões de saúde, pelo contato com agrotóxicos e fumo, e segundo por questões legais, pois a indústria fumageira proíbe o trabalho por indivíduos menores de 18 anos. Embora o fumo não seja uma cultura que demande trabalho durante o ano inteiro, as fases de

\footnotetext{
${ }^{6}$ Nesse sentido ver, por exemplo, Almeida et al. (2011), Marin, Redin e Costa (2014), Vogt (1997) e Wegner, Santos e Padula (2010).
} 
produção e colheita da cultura exigem dedicação por várias horas diárias, sendo, às vezes, necessária a contratação eventual de mão de obra no período de colheita.

Tangenciando a produção de biodiesel a partir do Projeto Girassol, os agricultores entrevistados disseram ter disponibilizado a área de terra requisitada (1 hectare) pela AFUBRA em conjunto com a mão de obra, e detinham o conhecimento de que o Projeto possuía cunho experimental nas propriedades. Em contrapartida, a Associação forneceu sementes, implementos, insumos agrícolas e assistência técnica gratuita. Após o período da colheita, os grãos eram transportados e beneficiados pela própria AFUBRA em sua unidade de bioenergia, localizada no município de Rio Pardo, resultando em biodiesel e torta de girassol. Contudo, é importante destacar que, segundo os entrevistados, a Associação ficava com 25\% do total da produção de biodiesel para compensar as despesas incorridas durante o processo de beneficiamento do grão, e os 75\% restantes retornavam para a propriedade rural; já a torta de girassol retornava em sua totalidade.

Quanto à utilização do biodiesel em máquinas e equipamentos de suas propriedades, os entrevistados destacaram um aspecto muito importante sobre a utilização do biodiesel: menos danoso à qualidade de suas saúdes e de suas famílias. Os agricultores entrevistados de Rio Pardo relataram que, quando utilizavam o biodiesel em seus tratores, percebiam que a fumaça lançada pelo sistema de escapamento não causava irritação em seus olhos, diferentemente daquela oriunda do diesel. Deste modo, o uso de biodiesel tornou-se uma alternativa sustentável por minimizar os impactos à saúde das pessoas (Pilar Social), por emitir menos gases do efeito estufa, em particular o dióxido de carbono (Pilar Ambiental), e por reduzir custos (Pilar Econômico), quando se analisa os efeitos deste na produção.

Apesar da percepção dos malefícios verificados quanto ao cultivo do fumo aos agricultores entrevistados de Rio Pardo, esta produção possui grande importância nas vidas dos agricultores ouvidos de Sinimbu, seja pela rentabilidade proporcionada na pequena propriedade, seja pela garantia de compra. Notou-se que há um conservadorismo em termos de produção por parte dos agricultores de Sinimbu, alinhado com as suas tradições familiares. Esta tradição pode ser entendida através da análise da cadeia produtiva do fumo (sistema integrado), que se encontra consolidada há bastante tempo, vinculando os agricultores a uma indústria de beneficiamento que proporciona técnicas, insumos, agrotóxicos, financiamentos e maior segurança em termos de garantia de compra da produção, porém determina o preço, as características e a qualidade do fumo. Já, entre os entrevistados de Rio Pardo, esse conservadorismo não foi identificado.

Quanto ao Pilar Econômico, ao serem questionados sobre os cultivos já praticados em suas propriedades e quais destes haviam promovido o maior retorno financeiro, os agricultores entrevistados demonstraram possuir uma visão idêntica diante do fumo. Todos afirmam que o fumo foi a cultura que originou o 
maior retorno financeiro quando comparado com outras culturas tradicionais, quanto daqueles que permanecem na produção: “O que me dá maior retorno é o fumo (risos)" (Agricultor 1); "O fumo sempre foi o carro-chefe" (Agricultor 2); mesmo entre aqueles que desistiram do cultivo: "O fumo é o que rende mais" (Agricultor 3).; "O fumo é o mais rentável [...] É o carro-chefe" (Agricultor 4).

Percebe-se o fumo possui a peculiaridade de propiciar ao agricultor uma renda elevada em uma área pequena. Konzen e Rohr (1988), Vargas (2013) e Wegner, Santos e Padula (2010) contribuem afirmando que a renda gerada pelo fumo, levando em consideração a pequena propriedade, raramente pode ser alcançada através de outras culturas.

Os agricultores de Sinimbu realizam a plantação de milho ${ }^{7}$ transgênico em conjunto com a de fumo, sendo que este último sempre foi considerado o "carrochefe" de suas propriedades. À guisa de exemplo, os agricultores entrevistados de Sinimbu destinam, em média, três hectares para a plantação de fumo, e colhem, aproximadamente, 600 arrobas $^{8}$. Considerando a produtividade média das propriedades rurais e o preço $(\mathrm{R} \$ 120,60)$ pago pelo mercado fumageiro aos agricultores, têm-se uma receita bruta total de $\mathrm{R} \$ 72.360,00$. O alto valor recebido pela venda do fumo é um fator determinante no quesito de escolha de um cultivo. Os resultados econômicos aproximaram-se quando comparados com os rendimentos dos agricultores entrevistados de Rio Pardo.

Por outro lado, o milho transgênico que é produzido pelos entrevistados de Sinimbu é destinado exclusivamente às cooperativas da região, que o direciona para o consumo humano ou para fabricação de ração para animais; já, o milho transgênico que é produzido pelos entrevistados de Rio Pardo visa o consumo interno da propriedade (alimentação humana e ração animal para porcos, galinhas e gado leiteiro). Percebe-se que em nenhum dos casos ocorre o beneficiamento do produto agrícola em biocombustível de primeira geração.

Em relação à produção leiteira, esta se caracteriza como uma atividade geradora contínua de renda aos agricultores entrevistados de Rio Pardo e compatível com atividades sazonais ou permanentes nas pequenas propriedades rurais, além de ser mais sustentável comparativamente à produção de fumo. Os entrevistados possuem, em média, 40 vacas com uma produção de 15 litros de leite por dia. Toda a produção leiteira é destinada para apenas uma cooperativa da região.

Realizando um comparativo com a receita bruta total gerada pelo fumo, o milho transgênico apresenta uma alta produtividade média aliada com uma baixa receita bruta total. Nas propriedades rurais dos entrevistados de Rio Pardo, têm-se uma

\footnotetext{
${ }^{7}$ De acordo com Vargas (2013), a produção de milho é considerada o segundo produto mais importante no que tange à composição de receita anual aos agricultores.

${ }^{8} \mathrm{Uma}$ arroba de fumo possui, aproximadamente, $15 \mathrm{~kg}$.
} 
produtividade média de 1.300 sacas em dez hectares plantados. Considerando a produtividade média das propriedades rurais e o preço $(\mathrm{R} \$ 22,92)$ pago pela cooperativa aos agricultores, têm-se uma receita bruta total de $\mathrm{R} \$ 29.796,00$. Destaca-se que o custo-benefício por hectare plantado do milho transgênico foi considerado pelos agricultores como muito oneroso e um dos principais problemas enfrentados é o preço pago pela cooperativa aos agricultores e o alto custo de aquisição da semente. Os resultados econômicos aproximaram-se quando comparados com os rendimentos dos agricultores entrevistados de Sinimbu.

Para melhor compreender a racionalidade econômica dos agricultores, o Quadro 2 ilustra um comparativo entre a produtividade média das propriedades e a receita bruta total gerada aos agricultores entrevistados de Sinimbu, observando os preços pagos a estes no mês de dezembro de 2013, entre a cultura do fumo e do milho transgênico. Considerando as receitas brutas totais do milho transgênico ( $\mathrm{R} \$$ $29.796,00)$ e a do fumo $(\mathrm{R} \$ 72.360,00)$, percebe-se que para possuir a mesma receita bruta gerada pelo fumo seriam necessários um pouco mais de 24,2 hectares plantados de milho transgênico, isto representa uma ocupação de $142 \%$ a mais de terras com a mesma finalidade. Já o fumo necessita de apenas 1,23 hectares para que proporcione a mesma receita bruta gerada pelo plantio de 10 hectares de milho transgênico. Percebe-se, assim, que a plantação de milho transgênico visando à substituição do fumo e à produção de biocombustível de primeira geração torna-se inviável pelo Pilar Econômico.

Quadro 2 - Comparativo de produtividade média e receita bruta gerada aos agricultores entrevistados de Sinimbu em dezembro de 2013 entre a cultura do fumo e do milho transgênico

\begin{tabular}{|c|c|c|c|c|c|}
\hline Culturas & $\begin{array}{c}\text { Produção } \\
\text { total }(\mathrm{kg})\end{array}$ & $\begin{array}{c}\text { Produção } \\
\text { por hectare } \\
(\mathrm{kg})\end{array}$ & $\begin{array}{c}\text { Preço pago } \\
\text { ao agricultor } \\
(\mathrm{kg} \mathrm{R} \$)\end{array}$ & $\begin{array}{c}\text { Receita bruta } \\
\text { total por } \\
\text { hectare }(\mathrm{R} \$)\end{array}$ & $\begin{array}{c}\text { Receita bruta } \\
\text { total da } \\
\text { propriedade } \\
(\mathrm{R} \$)\end{array}$ \\
\hline Fumo & 9.000 & 3.000 & 8,04 & $24.120,00$ & $72.360,00$ \\
\hline $\begin{array}{c}\text { Milho } \\
\text { transgênico }\end{array}$ & 78.000 & 7.800 & 0,382 & $2.979,60$ & $29.796,00$ \\
\hline
\end{tabular}

Fonte: Elaborado pelos autores com base em dados obtidos durante as entrevistas e em valores da FEE (2014) corrigidos pelo IGP-DI

Indubitavelmente, os agricultores entrevistados de Sinimbu possuem uma geração de renda acima da média com a produção do fumo, contudo, é uma cultura respaldada por práticas não sustentáveis, não contemplando o Pilar da Sustentabilidade Ambiental. Os entrevistados comentam que: "Se tivesse uma 
cultura que tivesse tanto lucro por hectare, como o fumo, eu ia largar logo, mas não tem [...] Ele é mais rentável e por enquanto eu, aqui, não tenho como largar [...] Como é que eu vou manter a minha propriedade? Não tem. Com o milho? [...] O fumo é o carro-chefe. O milho nem chega perto. É o fumo que mantém" (Agricultor 1); "Na pequena área, o fumo é que rende mais. Por isso que eu planto" (Agricultor 2).

Os entrevistados enfatizam que as indústrias fumageiras não permitem, através de seus contratos, que a venda do fumo seja realizada pelos agricultores para outros compradores interessados e que prometem melhores preços. Ressalta-se que as indústrias fumageiras acertam o preço mínimo do fumo muito antes da venda ser realmente efetivada, o que implica dizer que o produtor é penalizado por esta fixação de preço, ainda que reduza a incerteza quanto à venda. Os agricultores entrevistados de Rio Pardo alegam que as indústrias fumageiras transferem os seus prejuízos para os fumicultores, quando o volume exportado de fumo diminui e/ou a cotação do dólar apresenta baixa, através da má classificação do fumo, o que acarreta em um menor pagamento pela produção?.

No que tange à produção de etanol no município de Sinimbu a partir de cana-deaçúcar, essa mostrou-se inviável devido à localização geográfica dos agricultores entrevistados e por aspectos econômicos (alto custo da mão de obra durante as etapas de corte e de moagem da cultura). Por ser uma localidade com grande desnível, não há a possibilidade de abrir a área para a inserção de outros cultivos mais sustentáveis. Dependendo da cultura, ela demandará um maior ou menor uso de terras para o seu cultivo, fator a ser considerado no cálculo de sua viabilidade econômica, além de haver uma grande dificuldade no plantio e, neste caso, a mecanização torna-se ainda mais difícil. Em Rio Pardo, tanto o cultivo de cana-deaçúcar quanto de milho transgênico apresentaram viabilidade e poderiam ser destinados à produção de biocombustíveis, porém os entrevistados preferem destinar o milho transgênico para o próprio consumo e para a alimentação dos animais e não produzir a cana-de-açúcar.

Os entrevistados de Sinimbu acreditam que a produção de etanol somente mostrar-se-ia viável na região com a união de vários agricultores vizinhos, através de uma cooperativa ou associação, para que conseguissem montar uma unidade produtiva compartilhada (micro usina). Assim, haveria a produção de matériaprima e a sua transformação em energia, sendo o etanol utilizado pelos próprios agricultores em máquinas, equipamentos e automóveis.

Em relação à produção de biodiesel a partir de girassol, os agricultores entrevistados de Sinimbu relataram que houve prejuízos financeiros, pois os pássaros se alimentavam das sementes da flor, com o comprometimento

\footnotetext{
${ }^{9}$ Nesse sentido ver, por exemplo, Vargas (2013).
} 
considerável do rendimento do óleo de girassol, além do alto preço do quilo da semente. Em Rio Pardo, mesmo com alguns prejuízos financeiros causados pelos pássaros, os entrevistados pretendem voltar a participar do Projeto, caso seja reativado, em razão do retorno do biodiesel para o uso em seus maquinários e equipamentos, e da torta de girassol como insumo na formulação de ração animal, por possuir um elevado teor de proteína e influenciar a produtividade leiteira. $\mathrm{O}$ consumo do biodiesel e da torta de girassol reduz os gastos com a aquisição de combustíveis fósseis e de ração animal, respectivamente, e garante a sustentabilidade da propriedade. Ademais, menciona-se o potencial da flor do girassol para a atividade apícola, tornando possível a produção de mel e de pólen.

Percebe-se que o cultivo de girassol visando à produção de biodiesel pelos agricultores de Rio Pardo tinha por objetivo o consumo interno da propriedade. Mesmo que houvesse a intenção de venda de biodiesel pelos pequenos agricultores ao mercado, essa não seria possível em virtude da legislação brasileira ${ }^{10}$, que permite somente a produção e utilização de biodiesel para consumo próprio. Desta forma, a concepção do Projeto foi contemplada enquanto alternativa para o desenvolvimento sustentável e como opção para a diversificação da propriedade através da produção de matéria-prima para biocombustível de primeira geração e da utilização dos resíduos para alimentação animal.

Quanto ao Pilar Ambiental, os entrevistados de Rio Pardo mostraram possuir consciência sobre um dos principais impactos negativos que o fumo ocasiona ao meio ambiente: o desmatamento. Relataram ainda que este processo de devastação da cobertura florestal é necessário para que se obtenha a lenha para ser empregada como combustível nas estufas durante a etapa de secagem (cura) das folhas do fumo, as quais, posteriormente, serão processadas pelas indústrias fumageiras. Em contrapartida, os entrevistados de Sinimbu destinam uma parcela da área de suas propriedades rurais para a plantação de eucalipto para lenha. A prática do desmatamento, segundo Etges et al. (2002), causa sérios problemas ambientais sobre o solo, a água e a biodiversidade, bem como altera a paisagem local e o clima.

O tamanho médio da área das propriedades das famílias fumicultoras entrevistadas é de 29 hectares, sendo destinados 3 hectares para a cultura do fumo e cerca de 10 hectares para a do milho transgênico. No caso das famílias que deixaram de produzir fumo, o tamanho médio das propriedades é de 26 hectares, onde a cultura do milho transgênico ocupa quase 10 hectares e a pecuária, aproximadamente, 11 hectares. A área remanescente destina-se a outras maneiras de ocupação, como açudes, pastagens, vegetação nativa e/ou reflorestamento.

\footnotetext{
${ }^{10}$ Resolução da Agência Nacional do Petróleo, Gás Natural e Biocombustíveis, no 09, de 11 de fevereiro de 2015.
} 
De acordo com Lei n. 12.651, de 25 de maio de 2012, que estabelece a proteção da vegetação nativa nas propriedades rurais, os entrevistados de Rio Pardo disseram possuir a reserva mínima (20\%), e os de Sinimbu até 40\%. O excedente de vegetação nativa é visto como uma opção baseada na conservação da biodiversidade e na proteção da fauna silvestre e da flora nativa. A referida lei ainda prevê a exploração ou o corte de espécies nativas pelos agricultores com a condição de que haja o seu posterior reflorestamento. Destaca-se que essa prática e a opção dos agricultores de Rio Pardo se aproximam do que é defendido pela teoria do Desenvolvimento Sustentável, do ponto de vista de proteção ambiental.

Em relação à monocultura, os agricultores entrevistados de Sinimbu relataram terem plantado, durante todos seus anos dedicados aos cultivos, apenas fumo e milho transgênico, além de culturas de subsistência; e os agricultores entrevistados de Rio Pardo relataram terem plantado milho transgênico, trigo, girassol, aveia, pastagem e soja, assim como culturas de subsistência. Em ambos os casos, percebe-se que não houve a produção agrícola de apenas uma única cultura pelos entrevistados.

O processo de plantio do milho transgênico adotado pelos agricultores entrevistados de Rio Pardo e de Sinimbu é dado de forma direta. Segundo os entrevistados, este processo não causa danos ao meio ambiente, porque o plantio é realizado através de um manejo diferenciado do solo, que não é lavrado, e o único maquinário utilizado é a plantadeira. Como forma de proteger o solo da erosão, os agricultores deixam a palha do milho da safra anterior depositada sobre o solo, que serve como conservadora de umidade. No processo de plantio, a plantadeira abre o sulco no solo e deposita automaticamente as sementes de milho transgênico, descartando, assim, a utilização da mão de obra adicional, porém exige a utilização de uma substância química: o dessecante. Sobre a aquisição de dessecante, os agricultores de Rio Pardo disseram escolher de acordo com a sua toxicidade, por outro lado, em Sinimbu, os agricultores consideram o preço de venda.

Os entrevistados mencionaram o uso do acaricida/inseticida Bifentrina (marca comercial: Talstar 100 EC), dos herbicidas Sulfentrazona (marca comercial: Boral 500 SC) e Clomazona (marca comercial: Gamit 360 CS) e do fungicida Iprodiona (marca comercial: Rovral) no fumo. O primeiro com classificação toxicológica "III Medianamente Tóxico", o segundo "IV Pouco Tóxico", o terceiro "III Medianamente Tóxico", e o quarto "I Extremamente Tóxico", à saúde humana. Em relação ao potencial de periculosidade ambiental, os três primeiros agrotóxicos possuem classificação III de produtos perigosos ao meio ambiente, e o quarto, classificação II de produto muito perigoso ao meio ambiente. A esse 
respeito, há estudos ${ }^{11}$ que apontam a presença de danos potenciais à saúde dos agricultores devido ao contato com os agrotóxicos supracitados e à contaminação do meio ambiente.

As embalagens vazias de agrotóxicos utilizadas tanto na produção de fumo quanto na de outras culturas pelos agricultores entrevistados são armazenadas em um galpão para que sejam descartadas corretamente em um posto de recebimento ou nos estabelecimentos comerciais em que foram adquiridos. $\mathrm{O}$ descarte irregular das embalagens vazias de agrotóxicos não ocorre, porque os agricultores entrevistados possuem o conhecimento de que o não cumprimento da lei (Lei n. 9.974, de 6 de junho de 2000) poderá implicar em multas e à pena de reclusão. No entanto, percebe-se que não há uma consciência de que as embalagens vazias destes produtos constituem uma fonte de contaminação ao meio ambiente (água, solo) e à saúde da população, assim como a produção de milho transgênico, que não é vista como danosa ao meio ambiente e à saúde dos agricultores.

No tocante às consequências causadas pela produção e utilização de etanol ao meio ambiente, os entrevistados de Rio Pardo pensam que a utilização deste biocombustível ajudaria na conservação da natureza e que a sua produção não implicaria em resultados negativos na pequena propriedade. De acordo com a UNICA (2008), os resíduos gerados pela cultura da cana-de-açúcar, como a torta de filtro, a vinhaça e o bagaço, podem ser reaproveitados na propriedade: os primeiros como fertilizantes orgânicos em lavouras canavieiras, e o terceiro como alimentação animal. Ainda, a utilização da palha da cana-de-açúcar sobre o solo otimiza o processo de proteção e adubação deste. Por outro lado, os agricultores de Sinimbu pensam que a produção de biocombustíveis resultaria em uma intensificação da utilização de agrotóxicos e que dependendo da cultura, essa demandaria vastas áreas cultiváveis para a produção. O maior receio destes agricultores em iniciar o plantio de culturas para bicombustíveis é o de que as cooperativas exijam uma alta produtividade para que a compra seja garantida e efetivada.

\section{Considerações Finais}

O presente estudo buscou analisar a alternativa posta pelos biocombustíveis como estratégia de Desenvolvimento Regional Sustentável em substituição à produção de fumo, acolitando com os Pilares da Sustentabilidade (Social, Econômico e Ambiental), a partir da adesão do Brasil à Convenção-Quadro sobre Controle do Uso do Tabaco. Verificou-se que, devido à dependência da região ao cultivo de

\footnotetext{
${ }^{11}$ Nesse sentido ver, por exemplo, Almeida et al. (2011), Ascari, Scheid e Kessler (2012) Etges et al. (2002) e Riquinho e Hennington (2014).
} 
fumo, ainda não é possível ter a produção de biocombustíveis de primeira geração como substituta direta do fumo. Entretanto, para que o desenvolvimento sustentável seja atingido, é imprescindível que os Pilares da Sustentabilidade sejam examinados, através de uma perspectiva multidimensional, e que sejam incentivados programas e formações institucionais, como cooperativas e associações, de forma que ampliem os retornos econômicos e reduzam a fragilidade e a incerteza financeira.

O cultivo de girassol, para a produção de biodiesel, apresentou viabilidade social, econômica e ambiental satisfatória nos municípios de Sinimbu e de Rio Pardo. No entanto, os agricultores entrevistados de Sinimbu optaram por não continuar o cultivo e a desistir do Projeto devido a alguns prejuízos financeiros, principalmente quando comparado ao cultivo do fumo. Já em Rio Pardo, os entrevistados demonstraram novamente o interesse pelo Projeto, e, caso seja reativado, pretendem voltar a cultivar o girassol, visando à utilização do biodiesel em seus maquinários e equipamentos e da torta de girassol como insumo na formulação de ração para os seus animais.

A produção de etanol, a partir de cana-de-açúcar, pelos agricultores entrevistados no município de Sinimbu mostrou-se inviável pelo aspecto geográfico (áreas com grandes desníveis), que dificulta o plantio, a colheita e a mecanização agrícola, impactando, assim, fortemente nos Pilares Social e Econômico. Em Rio Pardo, a produção de etanol pelos agricultores entrevistados mostrou-se viável e contemplou os Pilares da Sustentabilidade. Em relação ao cultivo do milho transgênico, esse não é destinado à produção de biocombustível (etanol) por nenhum dos agricultores entrevistados. Os agricultores de Sinimbu preferem realizar a venda do milho transgênico para as cooperativas da região, e os agricultores de Rio Pardo optaram por destinar o milho transgênico para o próprio consumo e para a alimentação dos animais.

Percebe-se que, devido a alguns entraves, a produção de biocombustíveis de primeira geração pelos agricultores de Sinimbu tornou-se inexequível. Estes obstáculos fazem com que os entrevistados continuem cultivando o fumo, justamente por apresentar uma maior rentabilidade em comparação com outras culturas tradicionais na pequena propriedade, pelos "benefícios" apresentados pela cadeia produtiva do fumo, como técnicas, insumos, agrotóxicos e financiamentos, e pela garantia de compra da produção, ainda que essa última não esteja respaldada pela sustentabilidade. Contudo, a assinatura do Brasil à Convenção-Quadro sobre Controle do Uso do Tabaco torna a busca de alternativas produtivas obrigatória, e o uso de cultivos mais sustentáveis deveria ser priorizado, já que a fumicultura é uma atividade agrícola que não protege e tampouco garante a qualidade de vida dos indivíduos envolvidos durante as etapas do processo produtivo e causa severos impactos ambientais (desmatamento e contaminação do ar, da água e do solo). 
Tendo em vista os projetos de bioenergia protocolados pela AFUBRA, pode-se dizer que esses se inseriram no Programa Nacional de Apoio à Diversificação em Áreas Cultivadas com o Tabaco, que atuaram dentro da perspectiva do Desenvolvimento Sustentável, e que apoiaram os fumicultores entrevistados do Vale do Rio Pardo a buscarem um sistema produtivo sustentável e diversificado. É importante destacar que os entrevistados de Rio Pardo mostraram-se realmente interessados em produzir culturas mais sustentáveis, visando à produção de biocombustíveis, porém não as fazem pela ausência de incentivos governamentais, tanto no âmbito municipal quanto estadual ou federal. Estes incentivos são indispensáveis para a produção de matérias-primas de biocombustíveis de primeira geração.

O processo de propor programas de diversificação em áreas de cultivo do fumo é delicado, complexo, demanda pesquisas e subsídios governamentais, principalmente quando o foco está em regiões que possuem dependência econômica desta cultura, sobretudo na Região do Vale do Rio Pardo. É necessário que parcerias sejam realizadas com autoridades governamentais locais e regionais visando à disseminação e à consolidação de programas de diversificação ou de substituição do cultivo do fumo, adaptando-as à realidade estrutural regional produtiva. Para tanto, sugere-se, primeiramente, ações intersetoriais que devem ser trabalhadas contemplando múltiplas dimensões como meio ambiente, saúde, segurança alimentar, rendimentos econômicos, redução de incertezas comerciais, entre outras. Temos então uma cultura que deve ser extinta, o fumo, e uma que se propõe a promover a sustentabilidade, matérias-primas para combustíveis de primeira geração; o incentivo a essa transposição deveria ser visto como meio para o Desenvolvimento Regional Sustentável, respeitando a diversificação produtiva que ocorre em meio à agricultura familiar.

\section{Referências}

ABRAMOVAY, Ricardo. Desenvolvimento sustentável: qual a estratégia para o Brasil? Novos estudos - CEBRAP, n. 87, p. 97-113, 2010.

AGUIAR, Leonel. O discurso da sustentabilidade: uma genealogia. In: SCHAUN, Angela; UTSUNOMYIA, Fred. (Eds.), Comunicação e sustentabilidade: conceitos, contextos e experiências, p. 51-68. Rio de Janeiro: E-papers, 2010.

ALMEIDA, Eva Aparecida de et al. Agrotóxicos e o risco à saúde entre fumicultores. Publicatio UEPG: Biological and Health Sciences, Ponta Grossa, v. 17, n. 2, p. 133-139, jul./dez., 2011. 
ASCARI, Rosana Amora; SCHEID, Márcia; KESSLER, Marciane. Fumicultura e a utilização de agrotóxicos: riscos e proteção da saúde. Revista Contexto \& Saúde, Ijuí, v. 12, n. 23, p. 41-50, jul./dez., 2012.

ASSOCIAÇÃO DOS FUMICULTORES DO BRASIL (AFUBRA). A produção integrada de biodiesel e alimentos a partir do girassol: referências de uma pesquisa e suas indicações. Boletim Técnico. 1. ed. Santa Cruz do Sul: AFUBRA, 2011.

Bioenergia.

Disponível

em:

<http://www.afubra.com.br/bioenergia>. Acesso em: 6 de jun. de 2014.

ASSOCIAÇÃO DOS MUNICÍPIOS DO VALE DO RIO PARDO (AMVARP). Boletim da AMVARP. Disponível em: <http://www.amvarp.org.br/sites/8100/8162/AMVARP.pdf>. Acesso em: 20 de ago. de 2014.

BALSADI, Otavio Valentim. O mercado de trabalho assalariado na agricultura brasileira no período 1992-2004 e suas diferenciações regionais. Informações Econômicas, São Paulo, v. 37, n. 2, fev., 2007.

BARBIERI, José Carlos; CAJAZEIRA, Jorge Emanuel Reis. Responsabilidade social empresarial e empresa sustentável: da teoria à prática. São Paulo: Saraiva, 2009.

BARBOSA, Luciana Mendes. Agroenergia, biodiversidade, segurança alimentar e direitos humanos. Conjuntura Internacional, Belo Horizonte, ano 4, n. 33, 2007.

BONATO, Amadeu Antonio. Desafios e potencialidades para a diversificação na agricultura familiar produtora de tabaco. PNUD, out., 2013.

BRASIL. Decreto $\mathbf{n}^{\mathbf{0}} \mathbf{7 6 . 5 9 3}$, de 14 de novembro de 1975. Institui o Programa Nacional do Álcool e dá outras Providências. Diário Oficial da União. Brasília, DF, 1975.

Lei $\mathbf{n}^{\mathbf{0}}$ 9.974, de 6 de junho de 2000. Altera a Lei no 7.802, de 11 de julho de 1989, que dispõe sobre a pesquisa, a experimentação, a produção, a embalagem e rotulagem, o transporte, o armazenamento, a comercialização, a propaganda comercial, a utilização, a importação, a exportação, o destino final dos resíduos e embalagens, o registro, a classificação, o controle, a inspeção e a fiscalização de agrotóxicos, seus componentes e afins, e dá outras providências. Diário Oficial da União. Brasília, DF, 2000. 
Decreto $\mathbf{n}^{\mathbf{0}}$ 5.658, de 2 de janeiro de 2006. Promulga a ConvençãoQuadro sobre Controle do Uso do Tabaco, adotada pelos países membros da Organização Mundial de Saúde em 21 de maio de 2003 e assinada pelo Brasil em 16 de junho de 2003. Diário Oficial da União. Brasília, DF, 2006.

Lei $\mathrm{n}^{\mathbf{0}}$ 12.651, de 25 de maio de 2012. Dispõe sobre a proteção da vegetação nativa; altera as Leis nos 6.938, de 31 de agosto de 1981, 9.393, de 19 de dezembro de 1996, e 11.428, de 22 de dezembro de 2006; revoga as Leis nos 4.771, de 15 de setembro de 1965, e 7.754, de 14 de abril de 1989, e a Medida Provisória no 2.166-67, de 24 de agosto de 2001; e dá outras providências. Diário Oficial da União. Brasília, DF, 2012.

Resolução Agência Nacional do Petróleo, Gás Natural e Biocombustíveis, $\mathbf{n}^{\mathbf{0}}$ 09, de 11 de fevereiro de 2015. Estabelece, pela presente Resolução, os requisitos para cadastramento de produtor de biocombustível para fins de pesquisa e para autorização para produção de biocombustível para consumo próprio. Diário Oficial da União. Brasília, DF, 2015.

BRÜZEKE, Franz Josef. O problema do desenvolvimento sustentável. Papers do NAEA, n. 13, 1993.

CLUB OF ROME. About the Club of Rome. Disponível em: http://www.clubofrome.org/. Acesso em: 13 de jan. de 2014.

COSTA, Ricardo Cunha da; PRATES, Cláudia Pimentel Trindade. O Papel das Fontes Renováveis de Energia no Desenvolvimento do Setor Energético e Barreiras à sua Penetração no Mercado. BNDES Setorial, Rio de Janeiro, n. 21, p. 5-30, mar., 2005.

CRESWELL, John. Projeto de pesquisa: métodos qualitativo, quantitativo e misto. 2 ed. Porto Alegre: Artmed, 2007.

DEPARTAMENTO DE ESTUDOS SÓCIOECONÔMICOS RURAIS (DESER). Cadeia Produtiva do Fumo: Boletim especial DESER-ACT. Ed. dez., 2009.

ETGES, Virgínia Elisabeta et al. O impacto da cultura do tabaco no ecossistema e na saúde humana. Revista Textual, Porto Alegre, v. 1, n. 1, p. 14-21, nov., 2002.

FERES, Paulo Fernando Dias. Os biocombustíveis na matriz energética alemã: possibilidades de cooperação com o Brasil. Brasília: FUNAG, 2010. 
FUNDAÇÃO DE ECONOMIA ESTATÍSTICA (FEE). FEEDados. Disponível em: <http://feedados.fee.tche.br/feedados/\#!pesquisa $=0>$. Acesso em: 15 de jul. de 2014.

FURTADO, Celso. Introdução ao desenvolvimento: enfoque histórico-cultural. 3. ed. revista pelo autor. Rio de Janeiro: Paz e Terra, 2000.

GIL, Antonio Carlos. Como elaborar projetos de pesquisa. 4. ed. São Paulo: Atlas, 2002.

KONZEN, Otto Guilherme; ROHR, Ernani João. Produção de fumo em folha no Brasil e substituição potencial do fumo por outras culturas. In: XXVI Congresso Brasileiro de Economia e Sociologia Rural, 1988, Fortaleza, Ceará, Anais... Fortaleza, v. 3, 1988.

LAGO, André Aranha Corrêa. Estocolmo, Rio e Joanesburgo - O Brasil e as Três Conferências Ambientais das Nações Unidas. Brasília: Fundação Alexandre de Gusmão (IRB-MRE), 2006.

LEITE, Rogério Cezar de Cerqueira; LEAL, Manoel Régis Lima Verde. O biocombustível no Brasil. Novos estudos, São Paulo, n. 78, p. 15-21, CEBRAP, 2007.

MARIN, Joel Orlando Bevilaqua; REDIN, Ezequiel; COSTA, Felipe Ferrari da. Juventude rural e trabalho no cultivo do tabaco. Revista Latinoamericana de Estudios del Trabajo, v. 19, p. 159-194, 2014.

MINISTÉRIO DO DESENVOLVIMENTO AGRÁRIO (MDA). Programa Nacional de Diversificação em Áreas Cultivadas com Tabaco. Secretaria da Agricultura Familiar, Palácio do Desenvolvimento, Brasília, DF, 2014.

OLIVEIRA, Patricia Pereira Vasconcelos de et al. Primeiro relato do surto da doença da folha verde do tabaco no Brasil. Cadernos de Saúde Pública, Rio de Janeiro, v. 26, n. 12, p. 2263-2269, 2010.

ORGANIZAÇÃO MUNDIAL DA SAÚDE (OMS). Global status report on noncommunicable diseases. Geneva: World Health Organization, 2010.

RIO PARDO-RS. Dados Gerais. Disponível em: <http://www.riopardo.rs.gov.br/>. Acesso em: 27 de jun. de 2014. 
RIQUINHO, Deise Lisboa; HENNINGTON, Élida Azevedo. A. Cultivo do tabaco no sul do Brasil: doença da folha verde e outros agravos à saúde. Ciência \& Saúde Coletiva, Rio de Janeiro, v. 19, n. 12, p. 4797-4808, 2014.

SCOTTO, Gabriela; CARVALHO, Isabel Cristina de Moura; GUIMARÃES, Leandro Belinaso. Desenvolvimento sustentável. 3. ed. Petrópolis, RJ: Vozes, 2008.

SINDICATO INTERESTADUAL DA INDÚSTRIA DO TABACO (SINDITABACO). Exportações. Disponível em: $<$ http://sinditabaco.com.br/sobre-o-setor/exportacoes/>. Acesso em: 05 de ago. de 2015.

SINIMBU-RS. Dados Gerais. Disponível em: <http://www.sinimbu.rs.gov.br/>. Acesso em: 27 de jun. de 2014.

UNIÃO DA INDÚTRIA DE CANA-DE-AÇÚCAR (UNICA). Relatório de Sustentabilidade do Setor Sucroenergético Brasileiro. São Paulo, 2008.

VARGAS, Marco Antonio. Cultivo do tabaco, agricultura familiar e estratégias de diversificação no Brasil: uma análise comparativa em áreas de cultivo de tabaco no Vale do Rio Pardo. In: SILVEIRA, Rogério Leandro Lima da (Org.). Tabaco, sociedade e território: relações e contradições no Sul do Brasil. 1. ed. Santa Cruz do Sul: EDUNISC, 2013, p. 123-156.

VARGAS, Marco Antonio; OLIVEIRA, Bruno Ferreira de. Estratégias de diversificação em áreas de cultivo de tabaco no Vale do Rio Pardo: uma análise comparativa. Revista Economia e Sociologia Rural, Brasília, v. 50, n. 1, p. 157174, 2012.

VOGT, Olgario Paulo. A Produção de Fumo em Santa Cruz do Sul: 18491993. Santa Cruz do Sul: EDUNISC, 1997.

WEGNER, Douglas; SANTOS, Manoela Silveira; PADULA, Antonio Domingos. O Papel da Produção de Biocombustíveis Para o Desenvolvimento Local: Uma Análise no Arranjo Fumageiro Gaúcho. Gestão Contemporânea, Porto Alegre, v. 7, n. 7, p. 7-32, 2010.

WEID, Jean Marc Von Der. Agrocombustíveis: solução ou problema? In: ABRAMOVAY, R. (Org). Biocombustíveis: a energia da controvérsia. São Paulo: Editora Senac, 2009, p. 99-142. 
WHO FRAMEWORK CONVENTION ON TOBACCO CONTROL (WHOFCTC). Parties to the WHO Framework Convention on Tobacco Control. Disponível em: <http://www.who.int/fctc/signatories_parties/en/>. Acesso em: 02 de jul. de 2014.

YIN, Robert K. Estudo de caso: planejamento e métodos. 4. ed. Porto Alegre: Bookman, 2010. 
Endereço para correspondência:

Marcos Vinicius Dalagostini Bidarte - viniciusbidarte@hotmail.com Av. Itália, km 8 - Carreiros 96203-900 - Rio Grande/RS, Brasil

Ana Monteiro Costa - ana.mc98@gmail.com Av. Prof. Moraes Rego, 1235 - Iputinga 50670901 - Recife/PE, Brasil Telefone: (81) 21268361 